\title{
Determination of the frequencies of ten allelic variants of the Wilson disease gene (ATP7B), in pooled DNA samples
}

\author{
Charlotta Olsson $^{1,2}$, Erik Waldenström ${ }^{1}$, Kerstin Westermark ${ }^{1}$, UIf Landegren ${ }^{1,2}$ and \\ Ann-Christine Syvänen ${ }^{1}$
}

Molecular Medicine, ${ }^{1}$ Department of Medical Sciences, ${ }^{2}$ Department of Genetics and Pathology, Uppsala University, Sweden

\begin{abstract}
Wilson disease is an autosomal recessive disorder characterised by toxic accumulation of copper in liver, brain and other organs. The disorder is caused by mutations in the ATP7B gene, encoding a copper transporting P-type ATPase. Based on the number of known patients with this diagnosis in Sweden, the prevalence can be estimated to 1 in 250000 to 300 000, whereas the prevalence of Wilson disease has been estimated to be 1 in 30000 in other populations. We estimated the prevalence of Wilson disease by determining the Swedish population frequencies of two mutant alleles, making up approximately half the mutations in Swedish Wilson patients, in a large number of DNA samples. In addition we determined the allele frequencies of eight common single-nucleotide polymorphisms (SNPs) in the ATP7B gene. For the analyses we devised two strategies for analysing pooled DNA samples using the quantitative minisequencing method. The two procedures allowed sensitive identification of rare mutant alleles present as a mixture with an excess of the normal allele, as well as accurate estimation of the frequencies of the common SNPs in a large pooled DNA sample. European Journal of Human Genetics (2000) 8, 933-938.
\end{abstract}

Keywords: Wilson disease; ATP7B gene; minisequencing; DNA pools; single-nucleotide polymorphisms

\section{Introduction}

Wilson disease is an autosomal recessive disorder characterised by failure to incorporate copper into ceruloplasmin in the liver and to excrete copper from the liver to the bile, resulting in toxic copper accumulation predominantly in liver and brain. ${ }^{1,2}$ This results in acute and chronic liver disease and/or neurologic dysfunction. Diagnosis of Wilson disease is based on lowered levels of ceruloplasmin and increased free copper levels in urine and serum as well as on elevated copper concentrations in the liver. Wilson disease is lethal if left untreated, but if diagnosed, progression of the disease can be interrupted. However, as the typical biochemical findings may also be observed in other hepatic disorders, Wilson disease can sometimes be difficult to

Correspondence: Ann-Christine Syvänen PhD, Molecular Medicine, Department of Medical Sciences, Entrance 70, 3rd Floor, Research Department 2, Uppsala University Hospital, SE-751 85 Uppsala, Sweden. Tel: +4618662959; Fax: +46186625 19; E-mail: ann-christine.syvanen@medsci.uu.se

Received 31 May 2000; revised 19 July 2000; accepted 31 July 2000 diagnose. Furthermore, some patients neither show clinical signs of neurologic dysfunction nor do they have the typical corneal deposits of copper, the so-called Kayser-Fleischer rings. $^{3}$

The gene causing Wilson disease was cloned in $1993^{4-6}$ and named ATP7B. The protein encoded by this gene is a copper transporting P-type ATPase, which is predominantly expressed in liver and brain. ${ }^{7}$ Almost 200 mutations in the ATP7B gene have been reported world wide (http:// www.medgen.med.ual berta.ca/database. html). The two most common mutations in Swedish patients are a C-A transversion in exon 14 (C3207A) and a C-T transition in exon 13 (C2930T), accounting for $33 \%$ and $11 \%$ of the Swedish disease alleles, respectively. ${ }^{8}$ The preval ence of Wilson disease in Sweden has been estimated to be 1 in 250000 , whereas its prevalence has been estimated to be 1 in 30000 in other populations. $^{9}$ In the present study we determined the frequency of the two major disease-causing alleles in the ATP7B gene in a large Swedish population sample to investigate if the 10-fold lower prevalence of Wilson disease 
could be due to patients being missed in the clinic. In order to simplify detection of rare disease alleles we used a strategy in which pools of 10DNA samples were analysed for the presence of the two major disease-causing mutations in Sweden. The ATP7B gene also contains several singlenucleotide polymorphisms (SNPs) that are more common in the population than the disease-causing mutations. ${ }^{8,10}$ To determine the Swedish allele frequencies of eight of the common SNPs in coding regions of the ATP7B gene in the same sample material, we devised a different pooling strategy. A large pool, consisting of 2500 Swedish DNA samples, was analysed quantitatively to determine the proportion of the two sequence variants of each SNP, which reflects directly the allele frequencies at these sites in the Swedish population. In both strategies the pooled DNA samples were analysed by the solid phase minisequencing method. ${ }^{11}$ This PCR-based primer extension method identifies single nucleotide variations by incorporation of a single labelled nucleotide anal ogue. The analysis showed that the minisequencing method allows sensitive detection of minority sequence variants and accurate quantitative analysis of sequence variants present as a mixture in a pooled DNA sample.

\section{Material and methods DNA samples}

DNA was extracted from 2640 anonymous Swedish blood samples. DNA was extracted from the blood samples using the Wizard Genomic DNA Purification Kit (Promega, Madison, WI, USA). The DNA concentration of the samples was determined by measuring the absorbance at $260 \mathrm{~nm}$ in a spectrophotometer (DU 530 Beckman Instruments Inc, Fullerton, CA, USA). First, equal amounts of DNA from 10 individuals were combined into pools with DNA concentrations of $200-400 \mathrm{ng} / \mu \mathrm{l}$. These pools of 10 samples were further combined into a large 'super pool' containing an equal amount of DNA from 2500 individuals. The rare alleles were detected in pools of 10 samples and the frequencies of common SNP alleles were determined from the 'super pool'.

\section{PCR amplification}

The PCR primers were designed using the OLIGO program (Molecular Biology Insights Inc, Cascade, CO, USA) based on unpublished intronic sequences of the ATP7B gene, kindly provided by Drs Conrad Gilliam and Konstantin Petrukhin (Columbia University, New York). The sequence of the 5'-biotinylated forward primer for exon 13 was 5'-ACT CTG TCC TGT TIT CAG AAC CC-3' and that of the reverse primer was 5'-CGT GCT ACA GGC TGA CCT TGT GC-3'. The forward 5'-biotinylated primer for exon 14 was 5'-AGA CTG TGA TGT TTG ACA AGA CTG G-3' and the reverse primer was 5'-CCA AGT CCA CGT ACC TCT TTA-3'. The sequences of the primers for amplifying the exons containing eight SNPs in the ATP7B gene are given in Waldenström et al. ${ }^{8}$ The
DNA fragments containing the disease mutations or SNPs in the ATP7B gene were amplified from $200-400$ ng of DNA using 1.25 units of Taq DNA polymerase, $200 \mu \mathrm{m}$ dNTPs, the biotinylated primer at $0.2 \mu \mathrm{m}$ concentration and the other primer at $1 \mu \mathrm{m}$ concentration in $100 \mu \mathrm{l}$ of DNA polymerase buffer $\left(50 \mathrm{~mm} \mathrm{KCl}, 10 \mathrm{~mm}\right.$ Tris- $\mathrm{HCl} \mathrm{pH} 8.3,1.5 \mathrm{~mm} \mathrm{MgCl}_{2}$, $12.5 \mathrm{mg} / \mathrm{ml}$ bovine serum albumin, PE Biosystems, Foster City, CA, USA). The temperature was varied during 35 cycles of $94^{\circ} \mathrm{C}$ for $30 \mathrm{~s}$, an annealing temperature between $55^{\circ} \mathrm{C}$ and $65^{\circ} \mathrm{C}$ depending on the $T_{m}$ of the primers, for $30 \mathrm{~s}$ and $72^{\circ} \mathrm{C}$ for $45 \mathrm{~s}$.

\section{Minisequencing reaction}

Four $10 \mu \mathrm{l}$ aliquots of each PCR product were mixed with $40 \mu \mathrm{l}$ of binding buffer $(50 \mathrm{~mm}$ phosphate buffer $\mathrm{pH} 7.5$ containing $0.15 \mathrm{~mm} \mathrm{NaCl}$ and $0.1 \%$ Tween 20 ) in streptavidin-coated microtiter plate wells (Combi plate8, Labsystems, Helsinki, Finland) and incubated at $37^{\circ} \mathrm{C}$ for $1.5 \mathrm{~h}$ in a shaker (Thermomix 1415, Labsystems). The wells were washed 6 times with $40 \mathrm{~mm}$ Tris- $\mathrm{HCl}, \mathrm{pH} 8.8,1 \mathrm{~mm}$ EDTA, $50 \mathrm{~mm} \mathrm{NaCl}$ and $0.1 \%$ Tween 20 in a plate washer (Wellwash, Labsystems). The non-biotinylated strand of the PCR-product was removed by denaturation with $60 \mu \mathrm{l}$ of $0.1 \mathrm{~m} \mathrm{NaOH}$ for $3 \mathrm{~min}$. After washing as above, $50 \mu \mathrm{l}$ of a minisequencing reaction mix containing DNA polymerase buffer, $0.05 \mathrm{U}$ of Taq polymerase (PE Biosystems), $0.1 \mu \mathrm{Ci}$ of the appropriate $\left[{ }^{3} \mathrm{H}\right]-d N T P \quad\left(\left[{ }^{3} \mathrm{H}\right]-d A T P, \quad\right.$ TRK 633, $\left[{ }^{3} \mathrm{H}\right]-d C T P, \quad T R K 625$, [ $\left.{ }^{3} \mathrm{H}\right]$-dGTP, TRK 627, $\left[{ }^{3} \mathrm{H}\right]$-dTTP, TRK 576, Amersham Pharmacia Biotech, Amersham, UK) and $10 \mathrm{pmol}$ of the appropriate detection primer was added to the wells (Table 1). The plates were incubated at $50^{\circ} \mathrm{C}$ for $10 \mathrm{~min}$. The unincorporated label was removed by washing as above, and the detection primers were released with $100 \mu \mathrm{l}$ of $0.1 \mathrm{M} \mathrm{NaOH}$, and measured in a liquid scintillation counter (1414, Wallac, Turku, Finland).

Table 1 Position of the variant nucleotides and the minisequencing primers on the ATP7B gene

\begin{tabular}{lll}
\hline $\begin{array}{l}\text { Positions of mutations } \\
\text { and polymorphisms } \\
\text { (nt number) }^{\mathrm{a}}\end{array}$ & Exon & $\begin{array}{l}\text { Primer position } \\
\text { (nt number) }^{\mathrm{a}}\end{array}$ \\
\hline C2930T $^{\mathrm{b}}$ & 13 & $2953-2931^{\mathrm{c}}$ \\
C3207A $^{\mathrm{b}}$ & 14 & $3230-3208^{\mathrm{c}}$ \\
G1216T & 2 & $1196-1215$ \\
C1366G & 3 & $1346-1365$ \\
G2495A & 10 & $2475-2494$ \\
G2855A & 12 & $2835-2854$ \\
G2973A & 13 & $2953-2972$ \\
G3009A & 13 & $2989-3008$ \\
G3045A & 13 & $3025-3044$ \\
C3419T & 16 & $3399-3418$ \\
\hline
\end{tabular}

aThe nucleotide numbering is according to the published ATP7B cDNA sequence (accession no. U03464, GenBank); 'bthe two WD causing mutations analysed in 2640 individuals; 'the non-coding strand was analysed. 


\section{Interpretation of the result}

The result of the minisequencing assay is expressed as the ratio between the signals from the incorporated $\left[{ }^{3} \mathrm{H}\right]$-dNTP corresponding to the two sequence variants at each analysed site. A DNA sample with a 1:20 ratio between the mutant and normal sequence $(5 \%)$ was included in each series of pools as a reference sample for identification of DNA pools containing one mutant allele among the 20 alleles in each pool. The presence of a rare mutant allele in a pooled DNA sample is revealed by a signal ratio that is in the same range as that of the $5 \%$ reference sample, and elevated by more than two standard deviations compared with the ratio in a homozygous normal sample with $0 \%$ of the mutant allele. The allele frequencies ( $f$ ) of the common SNPs were calculated by comparing the signal ratios observed in the large pooled sample $\left(\mathrm{R}_{\text {pool }}\right)$ to the corresponding signal ratios in heterozygous samples $\left(\mathrm{R}_{\mathrm{Het}}\right)$, where the two alleles are present at a 1:1 ratio (50\%) according to the formulae:

$$
f_{\text {allelel }}=\frac{R_{\text {pool }} / R_{\text {Het }}}{1+R_{\text {pool }} / R_{\text {Het }}} ; f_{\text {allele2 }}=\frac{1}{1+R_{\text {pool }} / R_{\text {Het }}}
$$

\section{Results}

In the present study we determined the Swedish population frequencies of the two major mutant alleles of the ATP7B gene which cause the recessively inherited Wilson disease, and the population frequencies of eight common single polymorphisms (SNPS) in the ATP7B gene. The allele frequencies of both the rare alleles due to mutations in exon 13 and 14 of the ATP7B gene and those of the eight more common SNPs were determined by analysing pooled DNA samples quantitatively by competitive PCR using the solidphase minisequencing method. Two different pooling strategies were employed.

\section{Detecting rare alleles}

To estimate the optimal pool size for detecting rare Wilson disease-causing alleles, two standard curves were constructed by analysing samples containing mixtures of known amounts of the mutant and normal sequence in exons 13 and 14 (Figure 1). As can be seen from the standard curve in Figure $1 \mathrm{~A}$, samples containing significantly less than $1.5 \%$ of the sequence with a mutation in exon 13 can be distinguished from a homozygous normal sample (with $0 \%$ of the mutant sequence). The sensitivity of detecting the mutation in exon 14 of the ATP7B gene was about 3\% (Figure 1B). For both mutations there is a linear relationship between the ratio of the two sequence variants in the sample and that of the labelled allele-specific nucleotides incorporated in the minisequencing reactions from the detection limit up to at least $50 \%$ of the mutant sequence. Based on the observed sensitivity, equal amounts of DNA were pooled from sets of 10 samples to allow for errors in the DNA quantification,
A

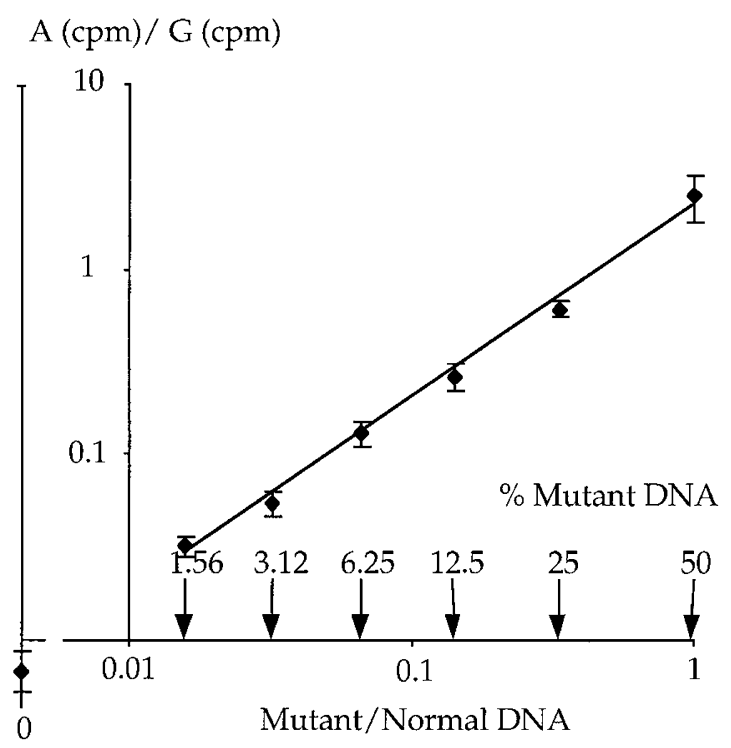

B

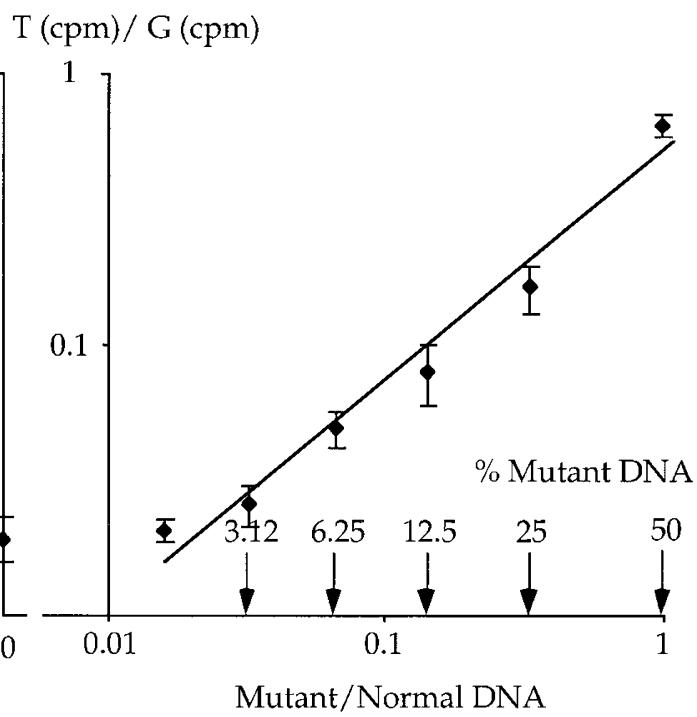

Figure 1 Solid-phase minisequencing standard curves. Minisequencing signal ratio plotted as a function of the ratio between the sequence containing (A) the C2930T mutation in exon 13 and (B) the C3207A mutation in exon 14 of the ATP7B gene and the normal sequence in mixed samples. Mean value and standard deviations of four parallel assays are shown. Arrows indicate the corresponding \% of mutant sequence in the mixtures. The signal ratios and their standard deviations in control samples without mutant sequence are given on the line to the left of the $y$ axis. The nucleotide corresponding to the non-coding DNA-strand was incorporated in the minisequencing reactions.

although the sensitivity determined from the standard curves would have allowed larger pools. With this pool size the mutant sequence would constitute $5 \%$ in pools including a single carrier individual. Altogether 264 pools were analysed 
for the two rare mutations in the ATP7B gene. The analysis revealed clearly elevated signal ratios compared with those in pools without a mutant allele and corresponding to $5 \%$ of DNA with a mutation in exon 14 of the ATP7B gene in four of the pools (Pool J, M, 9 and 192 in Table2). An elevated signal ratio in pool 158 (Table2) indicated that it contained one heterozygous sample with the exon 13 mutation of the ATP7B gene. The individual DNA samples in pools showing elevated signal ratios were analysed individually, and a heterozygous carrier of the Wilson disease mutation was identified in each of them. Based on this analysis, the Swedish population frequency of the mutant allele in exon 14 is expected to be $1 / 1300$ with a $95 \%$ confidence interval between $1 / 560$ and $1 / 4400$. The frequency of the exon 13 mutation is $1 / 5300$ with a wide $95 \%$ confidence interval of between $1 / 1200$ and $1 / 100000$. The frequencies of the exon 14 and 13 mutations estimated from the number of patients and the proportion of these mutations among the patients in Sweden are 1/760 and 1/2300, respectively.

\section{Detecting common alleles or SNPs}

The coding sequence of the ATP7B gene contains eight common SNPs of which three are silent, and five are missense changes. ${ }^{8}$ The frequencies of these sequence variants were determined rapidly and accurately using a different pooling strategy. An equal amount of DNA from 2500 individuals out of the 2640 analysed was combined into a 'super pool', which was subjected to quantitative analysis by the minisequencing method for each of the eight SNP sites. The ratios of the sequence variants in the super pool, corresponding to their population frequencies, were estimated from the ratio between the ${ }^{3} \mathrm{H}$-labeled dNTPs incorporated in the minisequencing reactions. The minisequencing ratio is influenced if the sequence immediately downstream of the analysed

Table 2 Result from the minisequencing analysis of pools containing DNA from Wilson disease carriers compared with negative pools and reference samples

\begin{tabular}{|c|c|c|c|c|c|}
\hline & \multicolumn{2}{|c|}{ Signals (cpm) } & \multicolumn{3}{|c|}{$\begin{array}{c}\text { Signal ratio } \\
\text { Mutant/Normal } \\
\text { Pos pool Neg pool } 5 \% \text { reference }\end{array}$} \\
\hline $\begin{array}{c}\text { Exon } 13 \text { G29 } \\
\text { Pool } 158\end{array}$ & $\begin{array}{l}30 \mathrm{~A} \\
215 \pm 26\end{array}$ & $1340 \pm 77$ & 0.16 & 0.010 & 0.23 \\
\hline $\begin{array}{l}\text { Exon } 14 \text { G32 } \\
\text { Pool J } \\
\text { Pool M } \\
\text { Pool } 9 \\
\text { Pool } 192\end{array}$ & $\begin{array}{l}207 T \\
420 \pm 21 \\
160 \pm 3 \\
120 \pm 40 \\
190 \pm 48\end{array}$ & $\begin{array}{l}4400 \pm 530 \\
5270 \pm 340 \\
2670 \pm 73 \\
2280 \pm 8\end{array}$ & $\begin{array}{l}0.096 \\
0.031 \\
0.045 \\
0.082\end{array}$ & $\begin{array}{l}0.0079 \\
0.0079 \\
0.0067 \\
0.018\end{array}$ & $\begin{array}{l}0.059 \\
0.059 \\
0.042 \\
0.065\end{array}$ \\
\hline
\end{tabular}

nucleotide position contains more than one of the same nucleotide, so that more than one ${ }^{3} \mathrm{H}$-labeled dNTP is incorporated for this allelic variant. That is the case for the G2495A and C3419T polymorphisms (Table3). In practice, the ratio is also affected by any sequence dependent misincorporation of ${ }^{3} \mathrm{H}$-labeled dNTPs by the DNA polymerase that may occur. To correct for these sequence contextdependent factors, heterozygous samples, in which the two alleles are known to be present in equal amounts, were used as quantification standards for each of the analysed SNPS (Table3). The allele frequencies of the SNPs were also determined by genotyping 20 individual DNA samples at each SNP. This analysis gave a result concordant with the quantitative analysis of the 'super pool'. Table 3 shows the Swedish allele frequencies of the eight SNPS.

\section{Discussion}

We applied two different pooling strategies for rapid and accurate determination of the Swedish population frequencies of ten sequence variants in the ATP7B gene. The frequencies of the two most common mutant alleles of the ATP7B gene causing Wilson disease in Sweden ${ }^{8}$ were determined by analysis of pooled samples, each of which contained an equal amount of DNA from 10 individuals. The number of identified carriers of these two ATP7B gene mutations coincides with the expected carrier frequency based on the number of diagnosed patients with Wilson disease and on the distribution of the exon 13 and 14 mutations among these patients. ${ }^{8}$ Our study supports the view that Wilson disease is well diagnosed in Sweden, and that the disease is really more rare in Sweden than in other countries, although the number of identified carriers was small.

A pooling approach has been proposed previously for population screening of the cystic fibrosis three base pair deletion mutation $\triangle \mathrm{F} 508$ by PCR-based heteroduplex analysis. A model for calculating the most cost-effective number of samples to be pooled based on the population frequency of the mutation to be detected was also presented. ${ }^{12}$ For rare mutant alleles, such as the Wilson disease alleles, the optimal number of samples per pool is in practice determined by the sensitivity of the method applied for detecting the minority allelic variant in an excess of the normal sequence. For hybridisation and sequencing methods the detection limit for genomic sequence variants is $10 \%$ or higher. ${ }^{13-15}$ The minisequencing method has proved to be more sensitive, as illustrated in a previous study, in which we were able to detect a rare recessive disease allele at the $1 \%$ level in pooled DNA samples. ${ }^{16}$ In detecting the two Wilson disease alleles, the detection limit of the minisequencing method was lower than $1 \%$ to $3 \%$, respectively. Based on our experience with 
Table 3 Allele frequencies of SNPs in the ATP7B gene, in a DNA pool from 2500 individuals and in 20 random individuals

\begin{tabular}{|c|c|c|c|c|c|}
\hline & & & & $\begin{array}{l}\text { Allel } \\
\text { Nor }\end{array}$ & $\begin{array}{l}\text { ion } \\
\text { int }\end{array}$ \\
\hline & & & Signal ratio & Super & Individual \\
\hline & Normal & Variant & Normal/Variant & pool & samples \\
\hline G1216T & & & & & \\
\hline Super pool & $1120 \pm 330$ & $1940 \pm 6$ & 0.58 & $0.44-0.56$ & $0.46-0.54$ \\
\hline Heterozygote & $1520 \pm 100$ & $2020 \pm 150$ & 0.75 & & \\
\hline C1366G & & & & & \\
\hline Super pool & $1800 \pm 170$ & $1180 \pm 210$ & 1.52 & $0.52-0.48$ & $0.50-0.50$ \\
\hline Heterozygote & $1870 \pm 4$ & $1340 \pm 30$ & 1.40 & & \\
\hline G2495A & & & & & \\
\hline Super pool & $2390 \pm 540$ & $160 \pm 50$ & 14.9 & $0.49-0.51$ & $0.46-0.54$ \\
\hline Heterozygote & $2780 \pm 50$ & $180 \pm 10$ & 15.4 & & \\
\hline G2855A & & & & & \\
\hline Super pool & $3500 \pm 220$ & $9460 \pm 250$ & 0.37 & $0.47-0.53$ & $0.33-0.66$ \\
\hline Heterozygote & $3760 \pm 250$ & $9150 \pm 560$ & 0.41 & & \\
\hline G2973A & & & & & \\
\hline Super pool & $840 \pm 60$ & $170 \pm 30$ & 4.94 & $0.92-0.08$ & $0.90-0.10$ \\
\hline & & & & $0.94-0.06^{b}$ & \\
\hline Heterozygote & $820 \pm 60$ & $1820 \pm 70$ & 0.45 & & \\
\hline 5\% A-allele & $1390 \pm 180$ & $250 \pm 20$ & 5.56 & & \\
\hline G3009A & & & & & \\
\hline Super pool & $200 \pm 20$ & $30 \pm 5$ & 6.67 & $0.87-0.13$ & $0.85-0.15$ \\
\hline & & & & $0.89-0.11^{0}$ & \\
\hline $\begin{array}{l}\text { Heterozygote } \\
5 \% \text { A-allele }\end{array}$ & $\begin{array}{l}260 \pm \pm 0 \\
340+20\end{array}$ & $240 \pm 20$ & 1.08 & & \\
\hline כ\% A-dilele & $340 \pm 20$ & $\angle U \pm 2$ & $1 /$ & & \\
\hline G3045A & & & & & \\
\hline Super pool & $2000+160$ & $80 \pm 8$ & 25 & $0.96-0.04$ & $0.90-0.10$ \\
\hline & & & & $0.97-0.03^{b}$ & \\
\hline Heterozygote & $1630 \pm 130$ & $1600 \pm 180$ & 1.01 & & \\
\hline 5\% A-allele & $1970 \pm 310$ & $150 \pm 10$ & 13.1 & & \\
\hline C3419T & & & & & \\
\hline Super pool & $20800 \pm 1070$ & $3300 \pm 180$ & 6.30 & $0.53-0.47$ & $0.74-0.26$ \\
\hline Heterozygote & $19700 \pm 1700$ & $3490 \pm 140$ & 5.64 & & \\
\hline
\end{tabular}

The nucleotides denoted as 'normal' are those given in the published sequence of the ATP7B gene (accession no. U03464, GenBank); the normal nucleotide is given on the left, followed by the nucleotide number in the ATP7B sequence; ${ }^{a}$ mean value and standard deviations of four parallel assays from the same PCR product; ${ }^{b}$ calculated using a $5 \%$ allele mixture as reference.

other mutations the detection limit is in most cases close to $1 \%$ when ${ }^{3} \mathrm{H}$-dNTPs are used as label, but higher with other labelled nucleotide analogues. ${ }^{17}$

Currently there is much effort to discover dense sets of SNPs to serve as markers to identify genes underlying common, multifactorial disorders by genome-wide linkage disequilibrium mapping or analysis of candidate genes. In the year 2000 SNP consortium has catalogued 300000 SNPs. ${ }^{18}$ Once the SNPs have been discovered, population-specific allele frequency databases will need to be established for them. To create allele frequency databases and perform association studies, a significant increase in throughput and reduction in costs of the current available assays for typing SN Ps is needed. One means would beto analyse alleles quantitatively in pooled DNA samples containing DNA from a large number of case and control individuals instead of genotyping individual DNA samples.

The concept of DNA sample pooling to reduce labour and costs in an association study was first suggested in 1985 by
Arnheim et al. ${ }^{19}$ In that study Southern blot hybridisation was used to search for restriction fragment length polymorphisms in the HLA class II locus that were in linkage disequilibrium with susceptibility to insulin-dependent diabetes in pooled samples containing DNA from tens of individuals. In several subsequent studies allele frequencies of microsatellite markers were determined by analysis of pooled DNA samples using PCR, followed by size separation and quantification of alleles. ${ }^{20-22}$ We earlier determined quantitatively the allele frequencies of a panel of SNPs to be used in forensics in large pooled samples containing DNA from several hundred individuals by competitive PCR using solid-phase minisequencing. ${ }^{11}$ In the present study the method proved accurate for quantification of eight common variant alleles in the ATP7B gene in a large 'super pool' of 2500 individuals.

We conclude that minisequencing primer extension is a suitable reaction principle for future cost-effective population-based screening of rare mutations, for determination of 
population frequencies of SNPs and for association studies using pooled samples on a large scale.

\section{Acknowledgements}

We thank Drs Joe Terwilliger, Anders Isaksson, Maria Lagerström and Sara Wedrén for their hel pful contributions. The study was supported by grants from the Swedish Research Council for Medical Sciences.

\section{References}

1 Bull PC, Cox DW: Wilson disease and Menkes disease: new handles on heavy-metal transport. Trends Genet 1994; 10: 246-252.

2 Danks DM: The Metabolic Basis of Inherited Disease. McGraw-Hill: New York, 1989, pp 1411-1431.

3 Gollan JL, Gollan TJ: Wilson disease in 1998: genetic, diagnostic and therapeutic aspects. J Hepatol 1998; 28: 28-36.

4 Bull PC, Cox DW: Long range restriction mapping of $13 q 14.3$ focused on the Wilson disease region. Genomics 1993; 16: 593-598.

5 Tanzi RE, Petrukhin K, Chernov I et al: The Wilson disease gene is a copper transporting ATPase with homology to the Menkes disease gene. Nat Genet 1993; 5: 344-350.

6 Yamaguchi Y, Heiny ME, Gitlin JD: Isolation and characterization of a human liver CDNA as a candidate gene for Wilson disease. Biochem Biophys Res Commun 1993; 197: 271-277.

7 Bull PC, Thomas GR, Rommens JM, Forbes JR, Cox DW: The Wilson disease gene is a putative copper transporting P-type ATPase similar to the Menkes gene. Nat Genet 1993; 5: 327-337.

8 Waldenström E, Lagerkvist A, Dahlman T, Westermark K, Landegren U: Efficient detection of mutations in Wilson disease by manifold sequencing. Genomics 1996; 37: 303-309.

9 Terada K, Schilsky ML, Miura N, Sugiyama T: ATP7B (WND) protein. Int J Biochem Cell Biol 1998; 30: 1063-1067.

10 Thomas GR, Forbes JR, Roberts EA, Walshe JM, Cox DW: The Wilson disease gene: spectrum of mutations and their consequences. Nat Genet 1995; 9: 210-217.

11 Syvänen A-C, Sajantila A, Lukka M: Identification of individuals by analysis of biallelic DNA markers, using PCR and solid-phase minisequencing. Am J Hum Genet 1993; 52: 46-59.
12 Gille C, Grade K, Coutelle C: A pooling strategy for heterozygote screening of the delta F508 cystic fibrosis mutation. Hum Genet 1991; 86: 289-291.

13 Farr CJ, Saiki RK, Erlich HA, McCormick F, Marshall CJ: Analysis of RAS gene mutations in acute myeloid leukemia by polymerase chain reaction and oligonucleotide probes. Proc Natl Acad Sci USA 1988; 85: 1629-1633.

14 Lai E, Riley J, Purvis I, Roses A: A 4-Mb high-density single nucleotide polymorphism-based map around human APOE. Genomics 1998; 54: 31-38.

15 Ahmadian A, Lundeberg J, Nyrén $P$, Uhlen $M$, Ronaghi $M$ : Analysis of the p53 tumor suppressor gene by pyrosequencing. Biotechniques 2000; 28: 140-144, 146-147.

16 Syvänen A-C, Ikonen E, Manninen $T$ et al: Convenient and quantitative determination of the frequency of a mutant allele using solid-phase minisequencing: application to aspartylglucosaminuria in Finland. Genomics 1992; 12: 590-595.

17 Syvänen A-C: From gels to chips: 'minisequencing' primer extension for analysis of point mutations and single nucleotide polymorphisms. Hum Mutat 1999; 13: 1-10.

18 Masood E: A consortium plans free SNP map of human genome [news]. Nature 1999; 398: 545-546.

19 Arnheim N, Strange C, Erlich $\mathrm{H}$ : Use of pooled DNA samples to detect linkage disequilibrium of polymorphic restriction fragments and human disease: studies of the HLA class II loci. Proc Natl Acad Sci USA 1985; 82: 6970-6974.

20 Lipkin E, Mosig MO, Darvasi A et al: Quantitative trait locus mapping in dairy cattle by means of selective milk DNA pooling using dinucleotide microsatellite markers: analysis of milk protein percentage. Genetics 1998; 149: 1557-1567.

21 Pacek P, Sajantila A, Syvänen A-C: Determination of allele frequencies at loci with length polymorphism by quantitative analysis of DNA amplified from pooled samples. PCR M ethods Appl 1993; 2: 313-317.

22 Shaw SH, Carrasquillo MM, Kashuk C, Puffenberger EG, Chakravarti A: Allele frequency distributions in pooled DNA samples: applications to mapping complex disease genes. Genome Res 1998; 8: $111-123$ 